\title{
PROSPECTIVE ANALYSIS OF FUNCTIONAL OUTCOME OF CLAVICLE FRACTURES TREATED BY PLATE OSTEOSYNTHESIS
}

\author{
Karthi M. N1, Premkumar T. C2, Kailash $K^{3}$
}

${ }^{1}$ Senior Assistant Professor, Department of Orthopaedics, Government Rajaji Hospital, Madurai Medical College, Madurai, Tamilnadu. ${ }^{2}$ Assistant Professor, Department of Orthopaedics, Government Rajaji Hospital, Madurai Medical College, Madurai, Tamilnadu. 3Junior Resident, Department of Orthopaedics, Government Rajaji Hospital, Madurai Medical College, Madurai, Tamilnadu.

\section{ABSTRACT}

\section{BACKGROUND}

Clavicular fractures are common injuries accounting for $2.6 \%$ of all fractures. Fractures of the middle third (or midshaft) account for approximately $80 \%$ of all clavicular fractures. The traditional view that the vast majority of clavicular fractures heal with good functional outcomes following non-operative treatment is no longer valid. Recent studies have identified a higher rate of non-union and specific deficits of shoulder function and hence each requiring careful assessment and individualised treatment and when indicated these fractures should be treated by primary operative fixation.

The aim of the study is to analyse the functional outcome of clavicle fractures treated by plate osteosynthesis.

\section{MATERIALS AND METHODS}

A total of 20 fresh patients of comminuted fracture clavicle from May 2010 to Dec 2011 were included in the study and were treated with orthogonal plating. These patients were followed at 6 weeks, 3 months, 4 months, 6 months and 12 months of followup and assessed in terms of time for union, range of motion and constant shoulder score.

Study Design- Prospective study in Government Rajaji Hospital.

\section{RESULTS}

At final follow-up $82 \%$ of patients have constant shoulder score above 90 with an excellent grade, $82 \%$ of patients had $>90 \%$, normal range of motion with $100 \%$ union rate on an average of 16 weeks.

\section{CONCLUSION}

Clavicle fractures should therefore be viewed as a spectrum of injuries with diverse functional outcomes, each requiring careful assessment and individualised treatment, and plate osteosynthesis should be preferred for the treatment of indicated middle-third clavicle fractures in active individuals.

\section{KEYWORDS}

Clavicle Fracture, Constant Shoulder Score, Plate Osteosynthesis.

HOW TO CITE THIS ARTICLE: Karthi MN, Premkumar TC, Kailash K. Prospective analysis of functional outcome of clavicle fractures treated by plate osteosynthesis. J. Evolution Med. Dent. Sci. 2018;7(15):1825-1828, DOI: 10.14260/jemds/2018/412

\section{BACKGROUND}

Clavicular fractures are common injuries accounting for $2.6 \%$ of all fractures. ${ }^{1}$ Fractures of the middle third (or midshaft) account for approximately $80 \%$ of all clavicular fractures..$^{1,2}$

The traditional view that the vast majority of clavicular fractures heal with good functional outcomes following nonoperative treatment is no longer valid. Recent studies have identified a higher rate of non-union and specific deficits of shoulder function in subgroups of patients with these injuries. $3,4,5,6,7$

These fractures should therefore be viewed in the spectrum of injuries with diverse functional outcomes, each requiring careful assessment and individualised treatment and when

'Financial or Other Competing Interest': None.

Submission 08-03-2018, Peer Review 25-03-2018,

Acceptance 28-03-2018, Published 09-04-2018.

Corresponding Author:

Dr. Premkumar T. C,

Assistant Professor,

Department of Orthopaedics,

Government Rajaji Hospital,

Madurai, Tamilnadu.

E-mail:drtcprem@gmail.com

DOI: $10.14260 /$ jemds $/ 2018 / 412$ indicated these fractures should be treated by primary operative fixation. Postoperative wound complications, scar dysaesthesia, infection, fixation failure and non-union are relatively common and may require revision surgery as does any other failed osteosynthesis.

\section{MATERIALS AND METHODS}

Study is conducted in Madurai Medical College and Government Rajaji Hospital on 20 patients with displaced/comminuted midshaft clavicle fractures from May 2010 to Dec 2011. All the patients were treated by open reduction and internal fixation with 3.5 reconstruction plate and screws.

\section{Inclusion Criteria}

Patients were included in the study if they had- (1). A completely displaced $(>2 \mathrm{cms}$ ) midshaft fracture of the clavicle (derived by clinical measurement), (2). A comminuted middle third fracture of the clavicle with inferior cortical defect, (3). A clavicle fracture associated with scapular neck fracture (floating shoulder), (4). Painful nonunion, (5). An age between sixteen and sixty years, (6). No medical contraindications to general anaesthesia and (7). Informed consent. 


\section{Exclusion Criteria}

Patients were excluded from the study if they had- (1) An age of less than sixteen years or greater than sixty years, (2) A fracture in the proximal or distal third of the clavicle, (3) Pathological fractures, (4) Nondisplaced or minimally displaced clavicle fractures.

\section{Operative Technique}

Under a general anaesthesia, the patient positioned in supine position with sandbag beneath the ipsilateral scapula. The involved shoulder prepared and draped, and an oblique incision made over superior surface of clavicle centring the fracture site.

The fracture site identified, and the fracture reduced and fixed with a $3.5 \mathrm{~mm}$ reconstruction plate after contouring. Plate is applied to the superior surface of the bone with the goal being a minimum of three screws in the main proximal and distal fragments in most cases. Comminuted fragments were secured with lag screws, if possible with care being taken to preserve soft tissue attachments. Bone grafting was performed in case with non-union.

The deltotrapezial fascia was closed with interrupted number- 1 absorbable sutures as a distinct layer followed by skin closure. No drains were used.

\section{Assessment}

Patients were seen at six weeks and at three, four, six and twelve months. Assessment included standardised clinical evaluation and completion of the constant shoulder score. Both an antero-posterior and a $20^{\circ}$ cephalad radiographs were made for each patient.
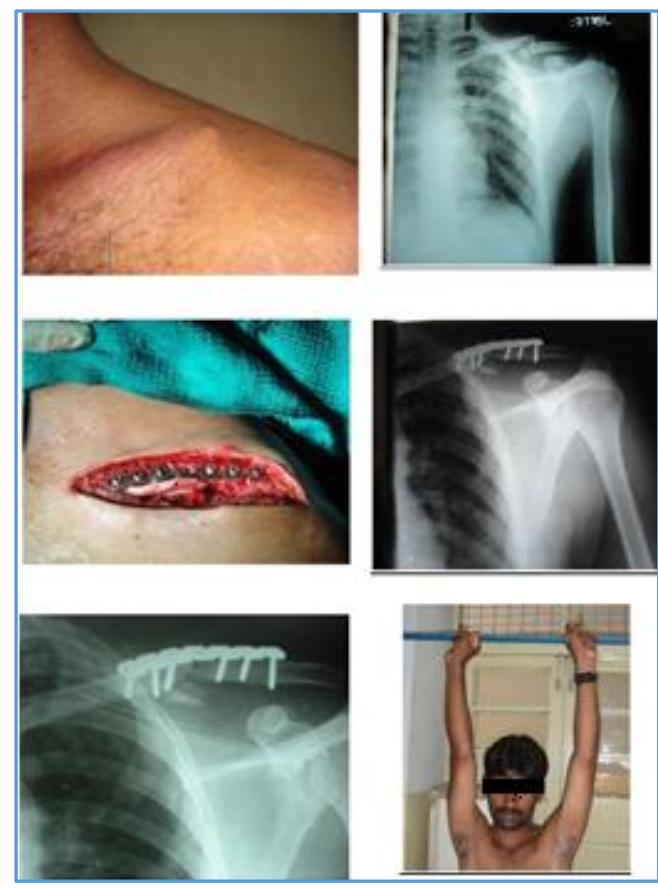

Case 1.
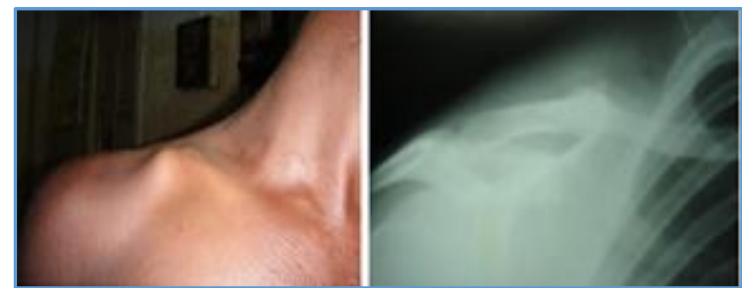
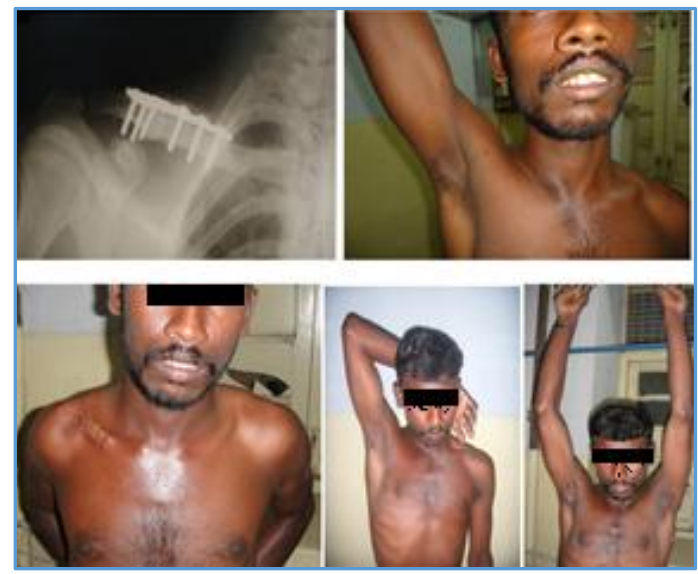

Case 2.
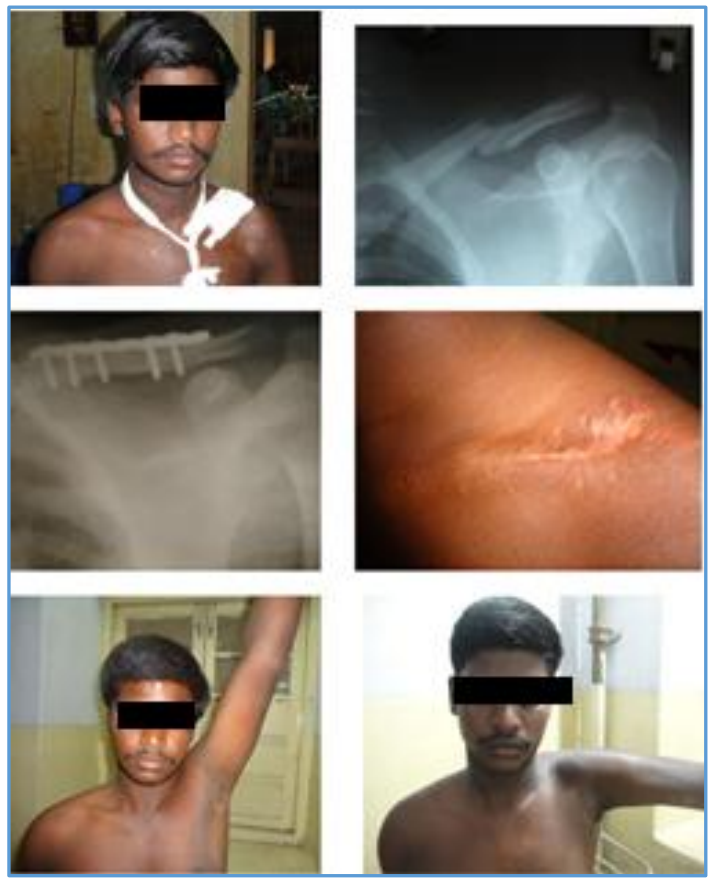

Case 3.
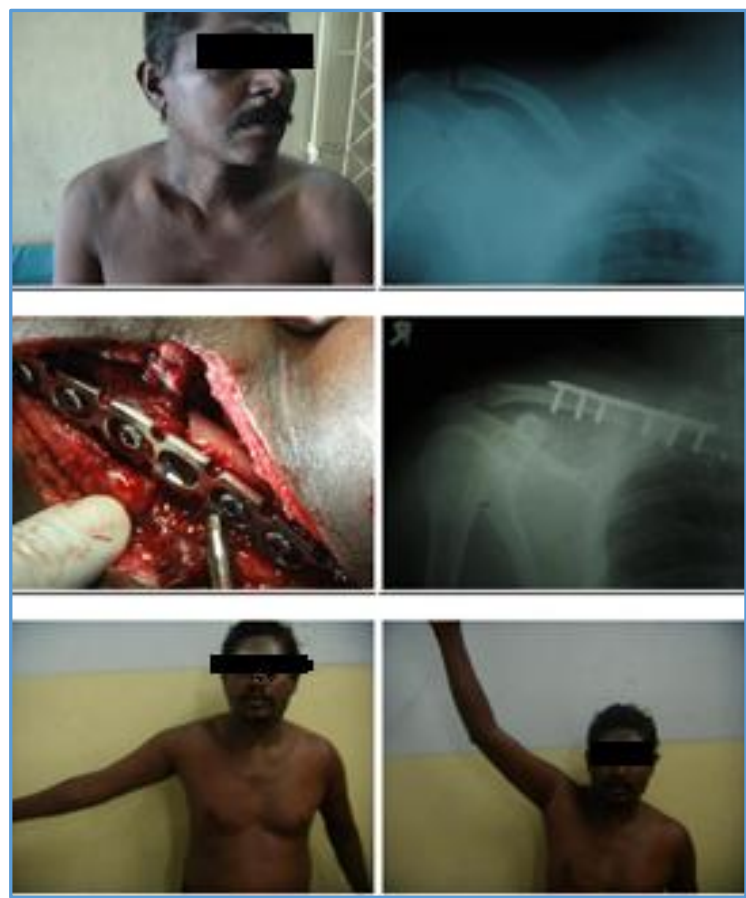

Case 4. 


\section{RESULTS}

Of the twenty patients (19 male and 1 female and most of them aged below 30 years) studied between May 2010 and Dec 2011, all had primary plate fixation except the one with painful non-union for whom plate osteosynthesis with bone grafting was done. Three patients were lost for follow-up and remaining 17 patients had a mean of 15.5 months follow-up.

All seventeen patients had fracture union in a mean of 16 weeks. Most of the patients (82\%) had constant shoulder score above 90 with an excellent grade except for three patients. Of these, two of them had wound infection and function improved after implant removal and one patient was a 60-year-old lady who developed shoulder stiffness due to improper follow-up and physiotherapy.

\section{Patient Satisfaction}

After the surgery, all patients except three patients were satisfied with their shoulder. Between operated and normal clavicle, there was mean length difference of 0.4 $\mathrm{mm}$.

\section{Return to Work}

Of the 17 patients in regular follow-up, thirteen patients had returned to their pre-injury levels of work and recreational activity. Two patients with post-op infection did not go to work. Patient with shoulder stiffness found difficult with their household activities.

\section{Range of Motion}

Range of motion was well maintained in all patients except the old lady who developed shoulder stiffness. The values were as of the normal contralateral shoulder, $82 \%$ of patients having $>90 \%$ of the normal function (Excellent grade). 17 patients had more than $90 \%$ of shoulder abduction, 94\% forward flexion and 92\% rotation arc.

\section{Rate of Union}

Fracture union was assessed with clinical and radiological means. Fractures united at an average of 16 weeks.

\section{Complications}

Two patients had wound infection and their plates were removed. One patient except for hardware prominence was doing well. One patient developed shoulder stiffness due to improper follow-up and physiotherapy. There was no nonunion/malunion in our study. There were no neurovascular complications. There were no refractures.

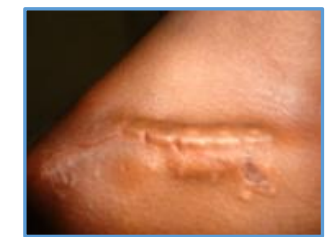

Hardware Prominence

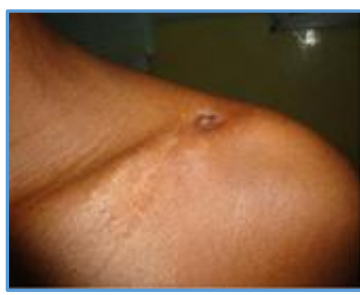

Post-Op Infection

\section{DISCUSSION}

There is a general consensus that clavicular fractures are best treated non-operatively. In the 1960s, Neer and Rowe reported on the non-operative treatment of clavicular fractures. However, more recent studies have shown that the union rate for displaced midshaft fractures of the clavicle may not be as favourable as once thought.

There were no non-union in our study. In a prospective, observational cohort study, Robinson et al described a consecutive series of 868 patients with clavicular fractures, 581 of whom had a midshaft diaphyseal fracture. They found a significantly higher non-union rate $(21 \%)$ for the displaced, comminuted midshaft fractures $(\mathrm{p}<0.05)$.

Similarly, in a study of fifty-two displaced midshaft clavicular fractures, Hill et al reported that eight patients had a non-union and sixteen patients had an unsatisfactory outcome on the basis of patient-oriented measures. They concluded that displacement of the fracture fragments by $>2$ $\mathrm{cm}$ was associated with an unsatisfactory result.

A meta-analysis of recent studies revealed that the rate of non-union for displaced midshaft clavicular fractures was $2.2 \%$ (ten of 460 patients) after plate fixation compared with $15.1 \%$ (twenty-four of 159 patients) after non-operative care and a relative risk reduction for non-union of $86 \%$. That meta-analysis also showed that primary plate fixation was contrary to prevailing opinion, a safe and reliable procedure.

Modern studies on primary plate fixation of acute midshaft clavicular fractures have described high rates of successful results with rates of union ranging from $94 \%$ to $100 \%$ and low rates of infection and surgical complications: a recent meta-analysis of plate fixation for 460 displaced fractures revealed a non-union rate of only $2.2 \%$. With improved implants, prophylactic antibiotics and better soft tissue handling, plate fixation has been a reliable and reproducible technique.

Late neurovascular compromise upto $6 \%$ was seen in patients treated conservatively due to non-union and excessive callus formation. In our study, we had no transient neurological abnormalities.

The range of motion was good and the mean constant score was above 90 in our study. On reviewing the literature, we found patients treated conservatively had substantial residual disability of the affected shoulder with minimal loss of muscle strength.

The advantages of internal fixation of clavicle fractures which includes early pain resolution, early return of shoulder function and potentially early return to work makes it an appealing option for the treatment of displaced fractures in active individuals.

Many different methods of operative fixation of mid-shaft clavicle fractures have been described. Intramedullary pinning techniques have been associated with a high number of complications such as pin migration and rotational instability and fixation with interfragmentary screws or wire sutures show insufficient immobilisation. As a result, we prefer rigid fixation with a plate osteosynthesis, which provides superior fracture stability and excellent clinical results in the treatment of acute fractures and non-unions.

In our study, the majority of complications were postoperative wound disorder (10\%). Literature review shows infection rate upto $10 \%$ for plate fixation of displaced midshaft fracture. The other major complication of our study 
was hardware irritation and prominence in $5 \%$ of patients. All cases were followed up regularly, we have no refractures till date.

Taking these percentages into account, we believe that operative treatment of acute middle-third clavicle fractures should be reserved for persons who wish to return early to activity and who accept the risk for potential complications. Especially, wound disorders and infection may lead to disasters and the patient should be duly informed before deciding to have the operation.

\section{CONCLUSION}

Internal fixation of clavicle middle third fractures by plate osteosynthesis has the advantage of early pain resolution, early return of shoulder function and potentially early return to work. Clavicle fractures should therefore be viewed as a spectrum of injuries with diverse functional outcomes, each requiring careful assessment and individualised treatment. Plate osteosynthesis should be preferred for the treatment of indicated middle-third clavicle fractures in active individuals.

\section{REFERENCES}

[1] Neer CS. Fractures of the clavicle. In: Rockwood CA, Green DP. (eds). Fractures in adults. 2nd edn. Philadelphia: Lippincott Co, 1984.

[2] Crenshaw AH. Fractures of the shoulder girdle, arm and forearm. In: Crenshaw AH. (eds). Campbell's operative orthopaedics. $8^{\text {th }}$ edn. St. Louis: Mosby Year Book, 1992:989-1053.

[3] Neer CS. Nonunion of the clavicle. J Am Med Assoc 1960;172:1006-11.

[4] Rowe CR. An atlas of anatomy and treatment of midclavicular fractures. Clin Orthop Relat Res 1968;58:29-42.

[5] Nordqvist A, Petersson CJ, Redlund-Johnell I. Midclavicle fractures in adults: end result study after conservative treatment. J Orthop Trauma 1998;12(8):572-6.

[6] Hill JM, McGuire MH, Crosby LA. Closed treatment of displaced middle-third fractures of the clavicle gives poor results. J Bone Joint Surg Br 1997;79(4):537-9.

[7] McKee MD, Schemitsch EH, Stephen DJ, et al. Functional outcome following clavicle fractures in polytrauma patients. J Trauma 1999;47(3):616. 